\title{
Discussion on the Transformation of Enterprise Production Management Model in the Environment of ERP*
}

\author{
Shaoqin $\mathrm{Lu}$ \\ School of Economics and Business Management \\ Changzhou College of Information Technology \\ Changzhou, China
}

\begin{abstract}
Production management is the process of production manufacturing and plays a crucial role in manufacturing enterprises. With the continuous progress and development of information technology and management methods, more and more companies use ERP systems for production management. After analyzing of tools such as master production schedule, material requirement planning, capability requirement planning and shop floor management in ERP system, the changes and impacts of the enterprise application ERP system to the enterprise production management methods are derived, and also get the problems that enterprises should pay attention to when applying the ERP system for production management.
\end{abstract}

Keywords-production management; plan management; workshop management; ERP

\section{INTRODUCTION}

Enterprise Resource Planning (referred to as ERP) system refers to a modern, systematic management philosophy based on information technology. It provides a platform for decisionmaking and operation management of the enterprise's leadership layer and employees. The ERP system integrates information technology and advanced management ideas, and has become a business model of modern enterprises. The benefits of the successful application of ERP systems have also been unanimously approved by the majority of manufacturing companies. [1]

With the continuous progress and development of information technology and enterprise management methods, ERP software system will be used in all aspects of corporate affairs management. ERP system can not only realize the data communication and sharing among internal departments of enterprises, but also can improve the speed and efficiency of business processing, and provide favorable data support for the

*Jiangsu University of Philosophy and Social Science Outstanding Innovation Cultivating Team Construction Project (No 2017ZSTD035) phased research results.

Changzhou College of Information Technology, Manufacturing and Internet Fusion Innovation Development Research Base (CXPT201702R) phased research results.

Jiangsu University Philosophy and Social Science Key Construction Base (2018ZDJD-B017) phased research results. enterprise's business decisions. The application of ERP system in manufacturing enterprises mainly includes product design, production management, raw material procurement, product sales, inventory management and financial management. Among them, the application effectiveness of ERP system in production management directly affects the productivity level of the enterprise and the delivery date of the product, at the same time; it is also conducive to improving the production capacity of enterprises and reducing the production costs of products, thereby enhancing the economic efficiency and comprehensive competitiveness of enterprises. The transforms and impacts of the ERP system on production management methods are mainly reflected in two aspects: production planning management and shop floor management.

\section{TRANSFORMS OF ENTERPRISE'S PRODUCTION PLANNING MANAGEMENT MODE}

\section{A. Using Master Production Schedule to Acheive the Balance Between Production and Demand}

The contradiction between supply and demand is the basic contradiction of the enterprise. The plan management of the enterprise mainly includes two aspects: the demand plan and the supply plan. At the same time, the plan is divided into the long-term plan and the short-term plan. There are five main aspects of plan management in ERP system: business strategy planning, sales and operations planning, Master Production Schedule (referred to as MPS), Material Requirements Planning (referred to as MRP), and Shop Floor Planning. From a time and function point of view, business strategy planning and sales operations planning are long-term plans for enterprises, their main purposes are to formulate the enterprise's long-term business goals and annual business plans that are broken down based on long-term business objectives. The Master Production Schedule, Material Requirements Planning, and Shop Floor Planning are the effective management tools in the ERP system and they are used to achieve the goals of long-term plans in the production and operation process. ${ }^{[2]}$

The Master Production Schedule is based on the sales plan or product inventory plan, according the actualization of the production plan for a certain product family, subdivides the 
market's demand of product family into production plans of each product, determines the plan for the production quantity of each specific end product in each specific time period. In the environment of enterprise's production by inventory-oriented, the master production schedule targets the inventory products and spare parts. In the environment of enterprise's production by order-oriented, the main production plan targets the final sale products and common parts. The final product refers to the final product to be manufactured, and delivered to customers, and known the product varieties and models. The specific time period is usually in weeks, or day, ten days, and months. The Master Production Schedule specifies what to produce and when to produce. The actualization of product family in business strategy planning and sales and operations planning makes them to be the main basis of production manufacturing, and plays a role in the transition from sales and operations planning to specific product production plans.

In terms of time, the planned time range of Master Production Schedule is called the plan horizon. It consists of three time periods: the first time domain, the second time domain, and the third time domain. Among them, the first time domain is also called the frozen time domain, which is equal to or slightly larger than the total assembly time of the final product. The production tasks in this interval are already undergoing final assembly and cannot be changed. The second time domain plus the first time domain is slightly larger than the production lead time of the final product, indicating that the production tasks within this time range have been confirmed and put into manufacturing. Changing the production plan will pay a higher cost and can only make a slight change. The third time domain is also referred to as the free time domain. The production tasks in this section are only planned and not confirmed, so they can be flexibly changed. During the production process, in order to increase the resilience of the production plan, efforts should be made to increase productivity and reduce the lead time of the plan as much as possible.

The basic principle of the Master Production Schedule is to determine the enterprise's production plan according to the enterprise's ability to achieve and break down the sales and operations planning objectives by balancing the production tasks, and to achieve a balance between production and demand over a longer time period, The enterprise's customer service level, inventory turnover rate and productivity level can be improved to maintain the realization of corporate sales goals and the feasibility and effectiveness of production planning. At the same time, the preparation of the Master Production Schedule should fully consider the availability of materials and the feasibility of production capacity. The Material Requirement Plan is generally used to determine the materials and components required for the Master Production Schedule, and the Rough-cut Capacity Planning is used to convert the Master Production Schedule into capacity requirements for key work centers to ensure for the feasibility.

\section{B. Using Material Requirements Planning to Achieve a Balance Between Production and Material Supply}

Material Requirement Planning is based on the final product demand information (MPS calculation results, independent requirements), Bill Of Material(referred to as BOM) and inventory data, to calculate the raw materials and components needed to produce the final product, to get the supply plan of raw materials and semi-finished production plans.. Material Requirement Planning mainly solves the problems of what materials are needed when producing final products, when materials are needed, and how many materials are needed. It decomposes the production plan of the MPS into production plans for self-made parts and production plans for outsourcing processed parts. And procurement plans for raw materials that are needed. In this way, MRP guarantees support for the MPS and guarantees the supply of materials used in the production process. [3]

The relationship of MPS, BOM, inventory and MRP is shown in following "Fig. 1". The procurement plan and the production operation plan are the results of MRP.

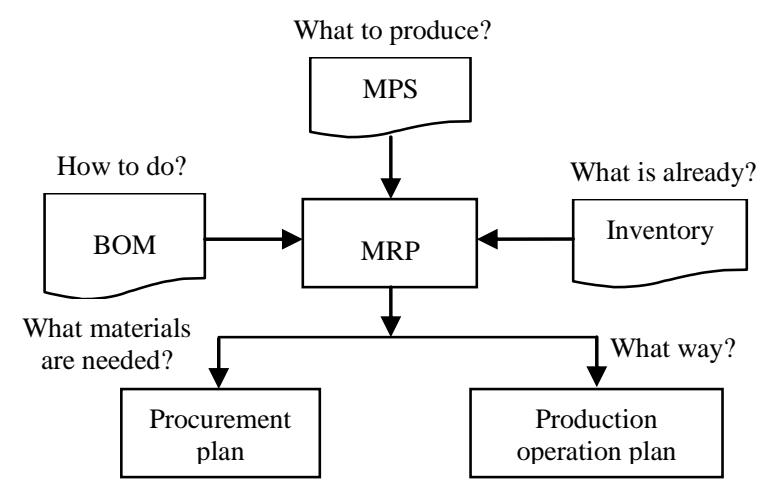

Fig. 1. The relationship of MPS, BOM, inventory and MRP.

The object of calculation of MRP is the related demand. The enterprise product can be divided into layers according to the conversion process from raw materials to finished products. And this forms a product structure document, thereby establishing the hierarchical affiliation and quantity composition relationship of the upper and lower materials. MRP can automatically calculate the related demand quantity of components, parts and raw materials that make up the product according to independent demand and BOM. In addition, the time segmentation is introduced in MRP, and the demand for related materials is time-scheduled. MRP can calculate the production schedule and outsourcing of various parts and components based on the lead time of each component material and the delivery date of independent requirements, the procurement schedule of the parts, so that it cannot only figure out what materials are needed, how many materials are required, but also accurately calculate when these materials are needed.

The MRP calculation process is the process of decomposing the demand of the final product from top to bottom and down to the requirements of various parts and components in the horizon. Among these, the relationship between the upper and lower materials is provided by the BOM. When the order is issued for a material plan, it also generates the demand for its lower materials, which are consistent in time and have a definite corresponding relationship in quantity. The 
calculations are broken down from the top down along the hierarchy of the BOM, from the beginning of the product until it is broken down to the lowest level (raw material) of the BOM. In this way, the completion of the lower-level material purchase plan or production plan is the support of raw materials for the upper-level material requirements, thereby realizing the coordination and balance between the production plan and the required raw materials. [4]

\section{Using Capacity Requirement Planning to Verify Production Capacity and Load}

There are three main results of the MPS and the MRP: shop work plan, material Procurement plan, and outsourcing processing plan. According to the information of the process route file, Capacity Requirement Planning (referred to as CRP) converts the material requirements of the self-made parts generated by MPS and MRP into the production capacity requirements of the workshop, and converts the planned production orders and uncompleted production orders to capacity requirements for each work center. The basic principle of CRP is to determine the quantity of products to be produced according to the planned production tasks, determines the quantity of production load required for production tasks according to the process route file, and compares the required loads with the existing working capacity of workshops. If the capacity is greater than the load required for the production task, the production plan is feasible. If the production capacity is less than the load required for the production task, the production plan needs to be adjusted. [5]

The capacity balance of a key work center is often referred to as a Rough-cut Capacity Planning (referred to as RCCP), and it is mainly oriented to the independent demand generated by MPS. The balance between capacity and load of all work centers is called detailed capacity planning. It is related to related demand, and it is mainly for all production workshops and work centers. RCCP is generally used to verify the feasibility of the MPS, and detailed capacity planning is used to reflect the load of all the workshops after MRP.

\section{REFORM OF ENTERPRISE'S WORKSHOP MANAGEMENT MODE}

\section{A. Dispatched Work Order Management}

Shop floor operations manage the schedule of production operations based on the material processing route files. The job content of the workshop management mainly includes verifying the planned orders generated by MRP, executing production orders, collecting production status information, monitoring work-in-process production, adjusting production measures, and completing production orders. In the environment of ERP, guiding the workshop to implement the CRP is achieved through the dispatched work orders. The dispatch work order is the most useful form of planners to implement the workshop production schedule. The dispatch work order not only records the tasks and related dates of the production order, but also shows the production processing department, work center, and processing priority. Daily dispatched work orders are generated by MRP calculations. The material shortage situation in the future has been forecasted. With the dynamic adjustment of the workshop work capacity and material inventory levels, the dispatched work orders can effectively prevent material shortage in the production process. In addition, the schedule of the workshop work plan is also carried out through top-down dispatched work orders, which can effectively reflect the adjustments and changes made by the production department to the manufacturing plan, and achieve the coordination between the production capacity of work centers and the quantity of materials stored in the warehouse. [6]

\section{B. Work-in-process Product Management}

Work-in-process can be determined for every work center by using the ERP system. By measuring the quantity of Workin-process at each work center in a certain time zone and comparing the high level with the low level, it is possible to determine the actual amount of change and queuing amount needed for the Work-in-process, thus forming feedback to the MRP system. ERP provides specialized production planning and control management tools. Using these tools for capacity planning and shop floor control can effectively reduce the quantity of work in process.

\section{FOCUS ON ISSUES IN THE ENTERPRISE PRODUCTION MANAGEMENT}

\section{A. Ensures the Accuracy of Inventory Records, Bills of Materials, and Routings}

If the data is inaccurate, serious consequences will result. Such as: warehouse inventory increases, resources cannot be used in a timely manner, production efficiency is low, production costs increase, delivery time is difficult to ensure and other issues. Therefore, the accuracy of the bill of materials, inventory and routing must reach more than $98 \%$, and it needs to be updated in a timely manner. [7]

\section{B. When Preparing for MPS, It Must Have a Long Enough Horizon}

MRP is driven by the MPS. During the calculation of the material requirement planning, the system will automatically calculate the material's purchase/production start date and end date and other information based on the relevant data set in the BOM. If the calculated material purchase or material production start date is before the planned horizon start date, the system will generate invalid data. [8]

\section{Allocates Purchase Orders to Multiple Suppliers}

In the preparation of MRP, the generated procurement plan should reasonably allocate purchase orders from multiple suppliers to ensure that the materials which be needed for production can be supplied in a timely manner, while also considering the production of materials, in-transit volume, scrapped amount, safety stock, and other Influencing factors. [9]

\section{CONCLUSION}

Under the ERP environment, the balance between production and demand in the enterprise's production management has been effectively achieved through the use of 
tools such as Master Production Schedule, Material Requirement Planning, Capacity Requirement Planning, and shop floor planning in the ERP system, and the balance between product production and material supply has been effectively realized, and also achieving verification between production capacity and load requirements. The changes brought about by the enterprise's production management methods under the ERP environment will be conducive to improving the productivity of enterprises, saving production costs, and increasing corporate profits, so as to continuously improve the management level of enterprises, increase the speed of response of enterprises to the market, ensure timely delivery to the enterprise's customers, and enhance the overall competitiveness of the enterprise.

\section{ACKNOWLEDGMENT}

The author acknowledges the valuable comments and suggestions of Editors, conference participants at the 3rd International Conference on Judicial, Administrative and Humanitarian Problems of State Structures and Economical Subjects (JAHP 2018).

\section{REFERENCES}

[1] Daryl Powell, "ERP systems in lean production: new insights from a review of lean and ERP literature," International Journal of Operations \& Production Management, vol. 33, pp. 1490 - 1510, 2013.

[2] Daryl Powell,Jan Riezebos, and Jan Ola Strandhagen. "Lean production and ERP systems in small- and medium-sized enterprises: ERP support for pull production," International Journal of Production Research, vol. 51, pp. 395-409, January 2013.

[3] LinKun Li,KaiChao Yu,and YiMing Li. "Research on Negative Inventory Balances Management of Modern Manufacturing Industry under ERP Environment," Springer Berlin Heidelberg, pp. 365-369, 2012.

[4] Manjunatha, H.K. and Shivanand, C.A, "A new paradigm of implementation of lean manufacturing through SAP R/3," International Journal of Mechanical Systems Science and Engineering, Vol. 2, pp. 187-192, 2008.

[5] Huai Ming Wang,Zhi Wei Cai,and Jie Yu. "Research and Development of Integrated Production Management System of Manufacturing Enterprises,” Key Engineering Materials, vol. 3351, pp. 582-587, 2014.

[6] Matsui, Y, "An empirical analysis of just-in-time production in Japanese manufacturing companies," International Journal of Production Economics, vol. 108, pp. 153-162, 2007.

[7] Wang Wei, and Meng Zheng. "Management Transformation and Innovation under the Trend of Industry 4.0," Enterprise Management. vol. 1, pp. 110-112, January 2016.

[8] Zhai Yue, and You De, "Ma Sisong.Intelligent Manufacturing Information Platform for Electric Machines," Electric Machines \& Control Application, vol . 44, pp. 119-125, December 2017.

[9] Yu Shi-kun, and Wang Bo. "Research on Application of Production Management between MRP and JIT Push-Pull," Modern Manufacturing Engineering, vol 1, pp. 65-68, January 2012. 